\title{
A construction of the exhibition evaluation support system based on GUI by visitors behavior analysis
}

\author{
Dae-Woong Kim \\ Faculty of Design, Department of Contents Creative Design \\ Kyushu University, Fukuoka, 815-8540, Japan \\ Joong-Youp Lee \\ Faculty of Design, Department of Contents Creative Design \\ Kyushu University, Fukuoka, 815-8540, Japan \\ Kousuke Kaneko \\ Graduate School of Information Science and Electrical Engineering \\ Kyushu University, Fukuoka, 819-0395, Japan

\begin{abstract}
The present thesis is on a construction of the system which supports exhibition evaluation of curators, which automatically collects, keeps, and totalizes objective data on visitor behavior in museums, and which comprehensively displays the results by tables and graphs. The system is composed by access points and mobile exhibition exposition devices in the museum operating together. Obtainable visitor information include a user number, an average staying period, contents use hour, and exhibition viewing frequency. Prototype experiment at museums shows that the system is effective in efficient data collection and exhibition evaluation and is expected to become an information collecting tool for visitor research and an exhibition evaluation tool for exhibition improvement.
\end{abstract}

Keywords: exhibition evaluation system, data automatic processing, information design

\section{PREFACE}

While museums play the role of preserving exhibition, they are the place where exhibition and visitors communicate. Curators and exhibition planners always scheme out an exhibition method for harmonious visitor-exhibition communication but it is hard to assess if one is effective for visitors. Heretofore, exhibition has been evaluated by a questionnaire and a follow-up survey in order to improve exhibition quality and visitor satisfaction. However, a questionnaire is instable in that replied data may drastically change depending on question items and questionnaire technique, which has room for questioner subjective intervention. A follow-up survey can collect objective data but cannot efficiently collect. Those conventional evaluation methods are a big burden for curators who have so much work and contribute little to improve visitor satisfaction and active communication through exhibition improvement. This is because the environment does not allow easy exhibition evaluation as mentioned above and an evaluation of exhibition

*Corresponding author.E-mail: dwkim@design.kyushu-u.ac.jp

Manuscript received Aug 29, 2011 ; accepted Sep.14, 2011 evaluation implementation is based on a thesis number of a curator. An exhibition evaluation system requires a system which can efficiently collect objective data and allows curators to easily evaluate exhibition.

\section{RESEARCH BACKGROUND}

2.1 The need for exhibition evaluation and museum current state

Exhibition evaluation is for assessing whether the planned exhibition project contents are effectively communicated to visitors and for establishing more effective information communication methods. Exhibition evaluation aims to gain a variety of knowledge of exhibition quality improvement and next exhibition plans by promoting exhibition improvement in order to increase visitor exhibition study and experience through detailed research and analysis of visitors. Visitor research is conducted to understand visitors, to figure out substantial methods to reflect visitor opinions on exhibitions, programs, facilities and services, and to gain information on their museum experience.

Japan has been ardently active about museum evaluation 
from the first half of 2000. This is because museum evaluation has become indispensable in order to adapt to social changes such as youth alienation from museums and an aggravation of economic environment. In February, 2000, a workshop and symposium took place at Lake Biwa Museum titled "Perspective on Museum Evaluation" inviting Mr. Brian McLaren, Ms. Minda Borun, and Mr. Ross J. Loomis from the United States and "Museum Evaluation and Improvement--Improving Skills" was held at Edo-Tokyo Museum in March, 2001. The Ministry of Education, Culture, Sports, Science and Technology (MEXT) has conducted "Museum Evaluation Activity Survey" aiming to grasp the current state of museum evaluation activities in Japan. Table 1 and Diagram 1 show the implementation state of exhibition evaluation at museums in Japan.

Table 1. Evaluation implementation state

\begin{tabular}{|c|c|c|c|c|}
\hline & National & Public & Private & Total \\
\hline $\begin{array}{c}\text { Implementing } \\
\text { museums }\end{array}$ & 21 & 408 & 128 & 557 \\
\hline $\begin{array}{c}\text { Not } \\
\text { implementing }\end{array}$ & 9 & 272 & 206 & 487 \\
\hline Total & 30 & 680 & 334 & 1,044 \\
\hline
\end{tabular}

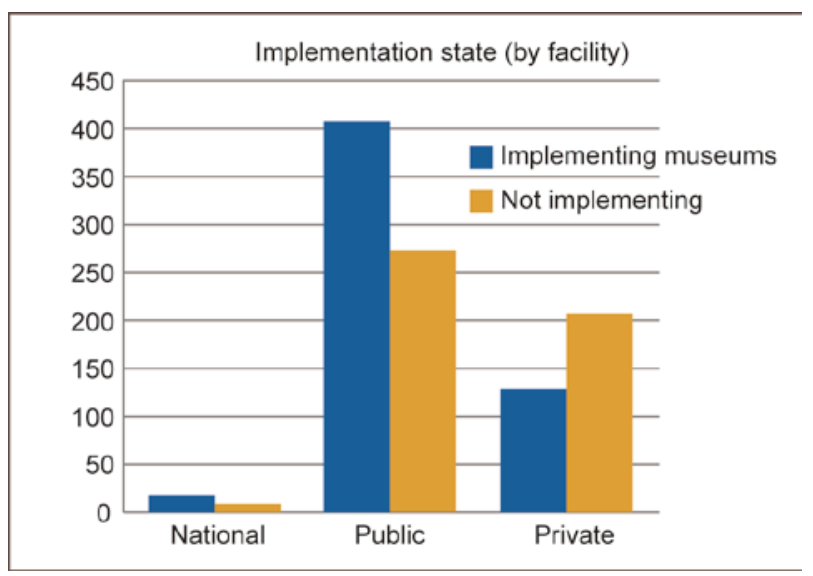

Fig. 1. Implementation state (by facility)

This survey indicates that 557 (53.4\%) museums implement evaluation activities and 487 (46.6 \%) museums do not implement them out of 1044 responded museums. Museum evaluation implementation rate by facility is national $70.0 \%$, public $60.0 \%$, private $38.3 \%$, and $53.4 \%$ in total. This survey shows that museum evaluation and exhibition evaluation are frequently taking place in Japan recently and some museums are trying to develop exhibition method incorporating evaluation. Museums in Asian countries including Japan still lack substantial exhibition evaluation and visitor research accumulation compared to the West where exhibition evaluation and visitor research had been taking place from the first half of twentieth century. In addition, exhibition evaluation methods are not established yet. Little research exists on exhibition exposition contents and visitor utilization situations and evaluation are not unveiled. The present research proposes advanced exhibition evaluation methods using mobile exhibition exposition devices.

\subsection{Visitor data collecting methods and discussion}

Four visitor data collecting methods (research methods) are introduced generally used at museums.

\subsubsection{Questionnaire}

Questionnaire is one of the most popular methods as visitor data collecting methods. This survey enables us to grasp visitor demography, viewing motivation, and satisfaction. It is advantageous in simply researching because visitors need only to select their choices for the provided questions from the museum. However, questionnaire is vulnerable to questioner subjective intervention and replied data may drastically change depending on question items and questionnaire technique. Furthermore, it is pointed out that visitor memory and degree of fatigue degrades the reply credibility in some cases.

\subsubsection{Follow-up survey}

This is a method to directly research visitor interest, staying period at museum and at each exhibition. Research items are route, exhibition viewing hour, viewing frequency. Museums can know problems of exhibition methods and a line of flow, and the clues of the solutions. However, follow-up survey data collection is inefficient because the number of subjects at a survey is a limited number. A stopwatch is used for timing and a pedometer is used for measuring distances but either of them is liable to cause researchers to mistake in obtaining data. Also, there is a possibility of having credibility gaps among obtained visitor information because visitors act differently when conscious of being observed and when not conscious of it.

\subsubsection{Research by recording}

Visitor information gained from video records includes visitor behavior, conversations, and interactions. Observation of the scene frequently takes place with interviews to visitors and museum staff. Research on visitor quantitative behavior from video records requires operating play, rewind, and pause buttons while reading behavior start time, writing the behavior and the time, and manually totalize, which takes a lot of time and trouble. This method requires researchers to do a lot of work and lays a big burden so it is not efficient. Qualitative evaluation also exists which collects and dictates visitor conversations by a microphone. However, it is unrealistic to analyze enormous amounts of recorded data in either of the cases.

\subsubsection{Wireless LAN system and RFID system}

A system has been proposed which can measure visitor staying hour using mobile devices which support wireless LAN and sensor technology such as IC tags. Advantages of visitor qualitative behavior data collecting methods using this kind of sensor system are the objectiveness and credibility of the gained behavior data and the capability of obtaining enormous amount of qualitative visitor data efficiently and in a short period. Mobile devices guide system can provide image and audio contents and guide visitors in corporation with maps. The use of mobile devices allows collection of visitor positions and viewed contents information. However, only few cases exist where visitor data collecting has been systemized for the sake of exhibition evaluation.

\subsection{Information visualization}

It is not easy to pick out necessary data from enormous amount of data. Although many algorithms exist which 
automatically extract necessary data, most times it is more intuitive and effective to manually pick out information. Data gained as output sometimes turn into "interpretation" which is overwhelming. Therefore, it is important to let a user recognize information clearly and simply. It goes without saying that using graphics is more understandable than using texts.

Information visualization is to help people to have deeper understandings and to present information in manageable style. This includes displaying data as diagrams, mapping on the computer screen, and display conversation style. Presenting data using these kinds of methods will allow users to have deeper understanding on data and to easily grasp an overall picture. An example of visualized information is "A Map of Winter Olympic Medals.” This system visualizes the number of gold medals at each country at every Olympic stored in database (Figure 2).

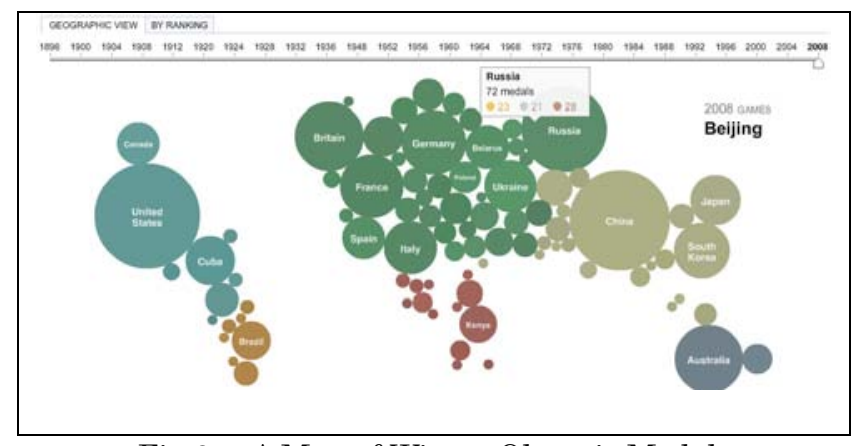

Fig.2. A Map of Winter Olympic Medals

The size of a circle becomes bigger in proportion with the number of gold medals. The circles are mapped in correspondence with world map so it is obvious which areas got more medals. Conversation function is also attached which enables users to check the number of medals at each Olympic scrolling the scroll bar above and moving the mouse on a circle shows a concrete figure.

\section{RESEARCH OBJECTIVES}

While it is prevalent to have guide system using mobile devices at museum, only few cases exist where visitor data collecting has been systemized for the sake of exhibition evaluation and the main stream is questionnaire and a follow-up survey. The present research aims to build and evaluate a system which automatically collects objective data and supports visitor behavior analysis and exhibition evaluation. Data collection systemization and designing interface which promotes efficient use of data will enable researchers to assess in what a visitor is interested in and if the exhibition method is effective for visitors.

\section{EXHIBITION EVALUATION SUPPORT SYSTEM DESIGN}

This chapter explains system building methods which collectively and automatically collect, totalize, and present visitor data.

\subsection{Design policy}

Collect objective data such position and time and support curators who evaluate exhibitions. Keywords for system design are "automation" and "visualizing." The present system automates all processes of exhibition evaluation. Data is collected and presented without curators directly managing and only the results are presented. Data for presentation is summarized to graphs and tables ad visualized. Visualization methods follow the thoughts at Chapter 2.3 and let the system have interactivity so that detailed data can be checked matching research objective while intuitively grasping data tendency. Likewise, support a data collection, exhibition evaluation, and exhibition improvement cycle (Figure 3).

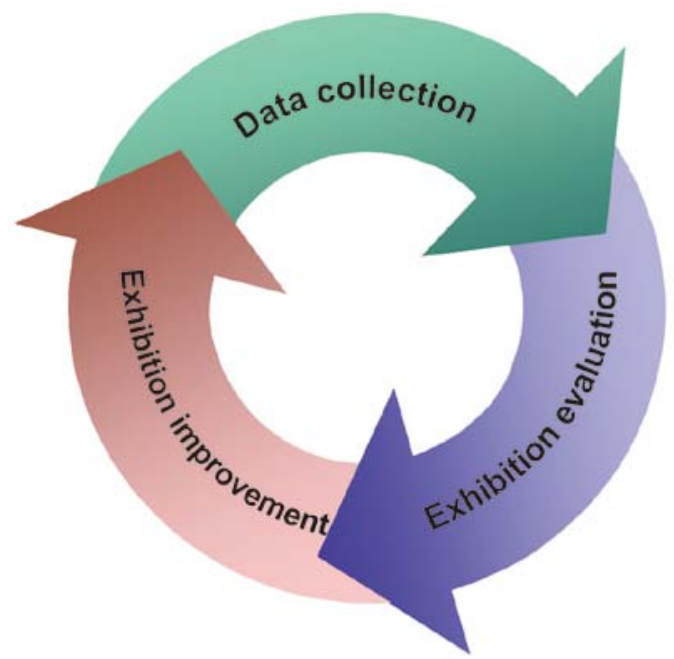

Fig. 3. Exhibition evaluation cycle

\subsection{System composition}

System is composed of mobile devices iPad (iPad applications) used as exhibition exposition navigation available for data collection, multiple access points set in the museum in order to identify user positions, server side system which manages and totalizes collected data, and client side system which presents totalized results to curators. Figure 4 shows the system composition.

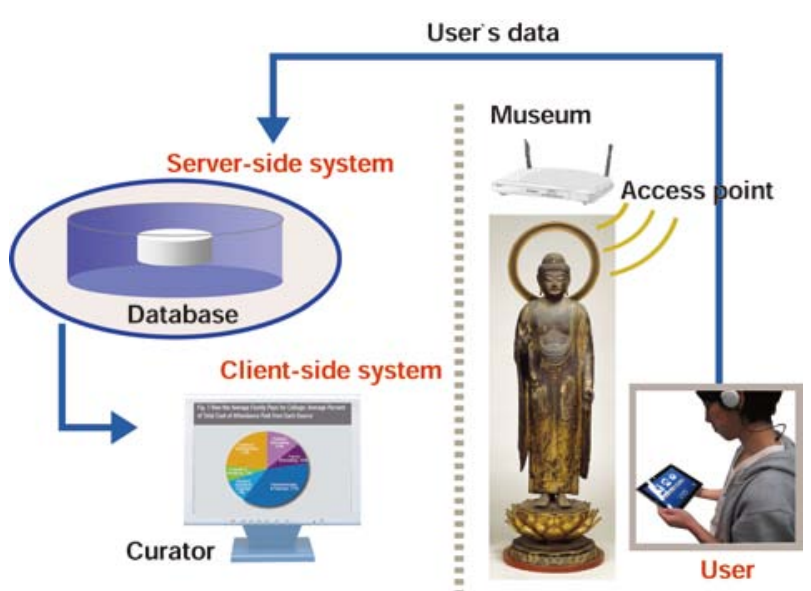

Fig. 4. System composition 
Users borrow an iPad, a mobile device, when visiting museum. When borrowing, users input information such as their age before viewing on the iPad and they carry it all the time in the museum. When a user comes to the range of exhibition contents viewing or the range where access points respond, data is automatically obtained. Obtained data is recorded in the iPad, sent to database server and managed and totalized after viewing. Totalized results are visually arranged and presented to curators at client side system (Figure 5).

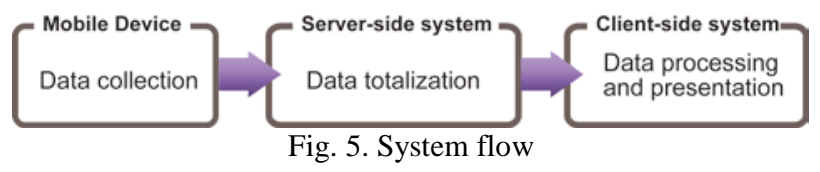

\subsection{System development environments}

The development environments of iPad applications which consists exhibition evaluation support system, server side system, and client side system are shown hereafter.

\section{(1) iPad application}

iPad applications are developed at Xcode. Xcode is an integrated development environment (IDE) provided by Apple. Development programming language is Objective-C. Objective-C conducts variable marking, method union, and class reading when dynamically operating not when compiling.

(2) Server side system

Development programming language is PHP, a server side script language. PHP can easily realize data exchange between client side system and database. MySQL is used for database management.

Small radio repeater PCW-0100 made by PicoCELA is used as access points. Radio relaying dispensed from Internet wiring and made it easy to add wireless LAN area, which realized wide range wireless LAN space.

\section{(3) Client side system}

Client side system is Adobe AIR application. Adobe AIR is an application execution environment developed by Adobe Systems and is technology to add Action Script execution environment to Operating Systems (OS). Contents written at Action Script can be executed at desktop of the OS without depending on the OS. Availability for data and service cooperation in the Internet and inclusion of rich animation and media technology made the application suitable for the system building. Open source library Tweener, publicized at Google Code, is used in order to execute tween on the animation object.

Adobe Flash Builder is used for system developments, which is an IDE. Development programming language is ActionScript 3.0.

\subsection{User data collection}

Collects data registered before viewing such as gender and age and behavior data (exhibition staying hour and exhibition exposition contents) while viewing exhibition. This section indicates data collection methods for evaluation.

\subsubsection{Previewing registration system at mobile devices}

We ask users to register before viewing on the mobile devices upon visiting for detailed evaluation. Registration items are shown hereafter.

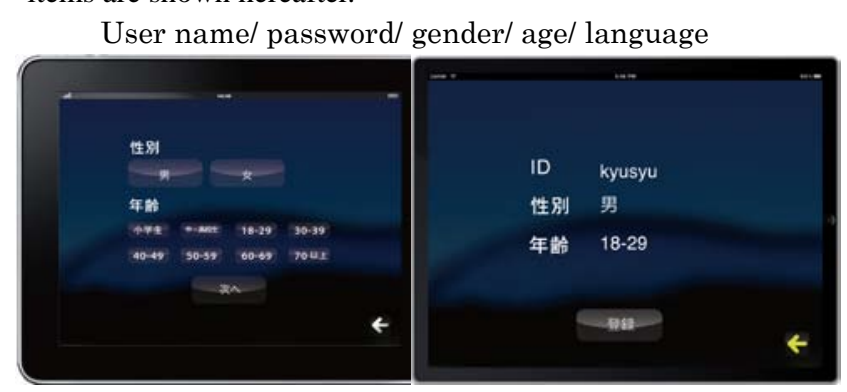

Fig. 6. A part of previewing registration screen and confirmation screen

Figure 6 is a part of registration screen. Using an iPad saves an user of difficult operations and enables an user to register with only touching the screen. The screen automatically changes as the user selects their choices. Even when a mistake is made, it is capable of correcting it since pushing "return" button will move to the previous screen. Inputting all items will change the screen to "confirmation screen" and input contents are confirmed. "Confirmation screen" on the right at Figure 6 shows that username is "Kyushu," gender is "male," and age is "18-29." When confirmed that there is no mistakes in the input contents at "confirmation screen," then pressing "register" button at the bottom of the screen will start wireless LAN communication and input data will be saved to server database. Database access time is saved as user viewing start time in the same manner with input data. The user then starts viewing exhibition. Registered username and password can be considered to be used again when revisiting museum or study on the website.

\subsubsection{User information collecting methods in museums}

(1) Positioning information collecting methods

User positions in the museum can be determined by mobile devices detecting radio waves from $\mathrm{Wi}-\mathrm{Fi}$ access points. The mobile device always receives and updates positioning information by scanning if there are Wi-Fi access points nearby. Information mobile devices can obtain from $\mathrm{Wi}-\mathrm{Fi}$ access points include Wi-Fi field intensity and access points MAC address.

-What is field intensity?

It digitalizes radio signal intensity when mobile devices receive radio waves sent out from access points. It is utilized to control send out field at wireless communication such as wireless LAN and Bluetooth.

-What is MAC address?

It is a physical address uniquely allocated to hardware. The present system uses it to recognize access points.

User positions are identified by Wi-Fi field intensity and MAC address. Mobile devices will contain positioning information database associated to the two figures and positions. Mobile devices identify their positions by comparing positioning information database with the strength of field intensity and with the access point positions (Figure 7). 


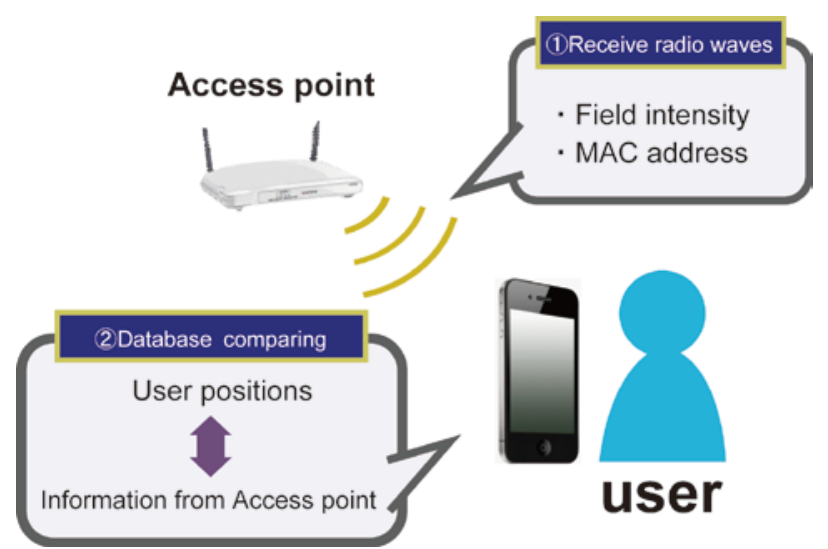

Fig. 7. Positioning information collection order

For example, access points are set as shown in Figure 8. Nine access points are set and the method to detect the area a user is present out of four areas is shown below.

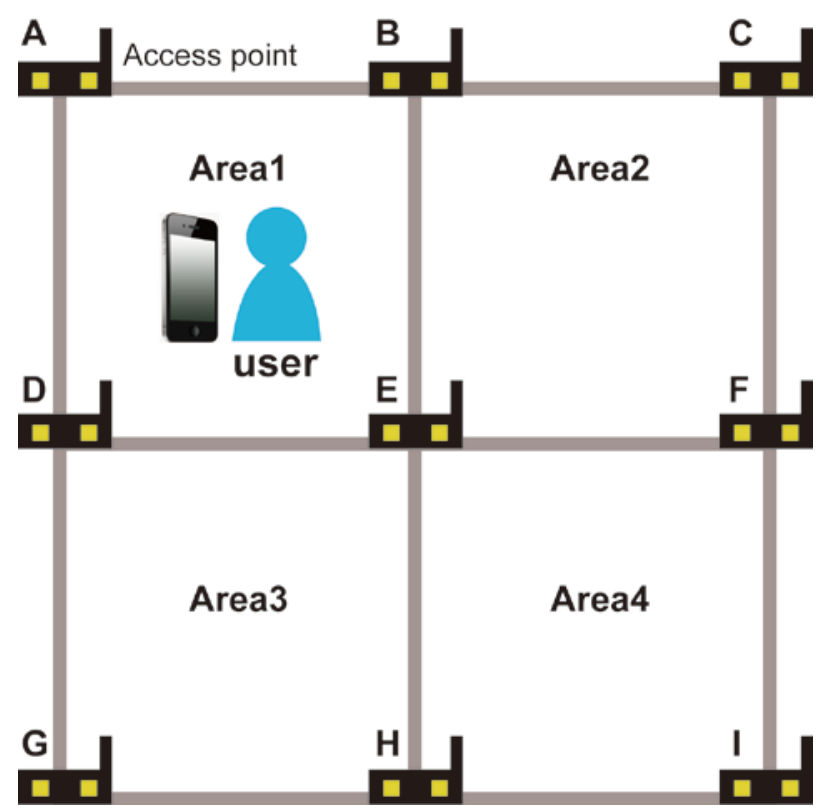

Fig. 8. Positioning information acquisition example

Instead of MAC address, each access point is named from A to I. We consider the case when positioning information database is constructed as Table 2.

Table 2. positioning information database construction example

\begin{tabular}{|c|c|c|c|c|}
\hline Area & AP & AP & AP & AP \\
\hline $\mathbf{1}$ & $\mathrm{A}=45$ & $\mathrm{~B}=47$ & $\mathrm{D}=46$ & $\mathrm{E}=45$ \\
\hline $\mathbf{2}$ & $\mathrm{B}=41$ & $\mathrm{C}=42$ & $\mathrm{E}=43$ & $\mathrm{~F}=40$ \\
\hline $\mathbf{3}$ & $\mathrm{D}=50$ & $\mathrm{E}=46$ & $\mathrm{G}=49$ & $\mathrm{~F}=44$ \\
\hline $\mathbf{4}$ & $\mathrm{E}=48$ & $\mathrm{~F}=49$ & $\mathrm{H}=45$ & $\mathrm{I}=49$ \\
\hline
\end{tabular}

Each area has set multiple access points and their field intensity threshold as the conditions to detect the area. When received field intensity goes over the threshold value, the access point becomes the likely candidate for detection. Suppose that the user present area is identified when three of the four access points fulfill the conditions and the mobile device has detected access points nearby. The result for this is as follows.

【Received access point name and field intensity】

\begin{tabular}{|l|}
\hline Access point A: field intensity 45 \\
Access point B: field intensity 44 \\
Access point C: field intensity 39 \\
Access point D: field intensity 47 \\
Access point E: field intensity 46 \\
Access point F: field intensity 33 \\
Access point H: field intensity 36
\end{tabular}

Field intensity of access points $\mathrm{A}, \mathrm{D}$, and $\mathrm{E}$ are over the threshold value of area 1 set at database. In this case, the user is assessed to be present in area 1 .

\section{(2) Mobile devices operation history data collection}

When user positions are detected using positioning information, exhibition exposition contents of the nearby exhibition will be available. Mobile device screen shows exhibition icons supporting exposition contents (Figure 9).

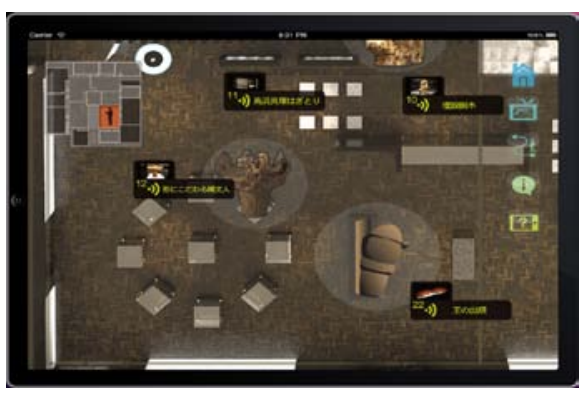

Fig. 9. Exhibition exposition contents icons

Clicking an icon will play exhibition exposition contents. Exhibition evaluation support system saves contents ID for contents identification every time the user selects an icon. When the user finishes viewing contents, slide bar value indicating the play situations at the time will be collected and will be saved as contents play hour together with contents ID (Figure 10).

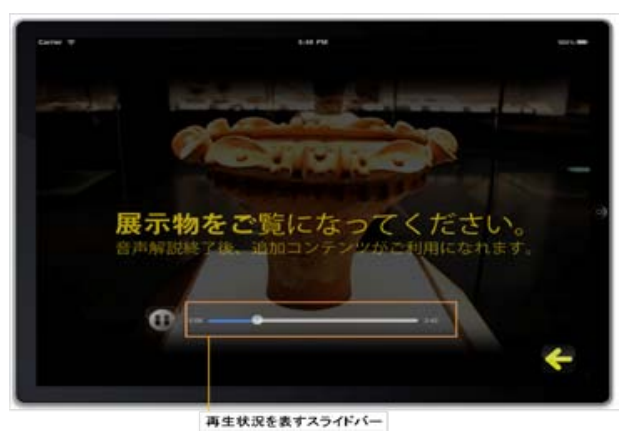

Fig. 10. Contents play screen

Slide bar value is collected because computing contents play hour by the gap of the time contents started playing and the time contents ended will contain the possibility of adding the period contents have been paused in the middle. When a user finishes museum viewing, operation history data is sent to the 
server side system explained below. Collected data is totalized and utilized as user data for exhibition evaluation.

\subsection{Data management and totalization}

Data collected by mobile devices will be saved to server database. Server side system totalizes the data in accordance with a request from client side system. Server side system is explained hereafter which saves and totalizes data.

\subsubsection{Database design}

The present system builds database because systematical data organization is required when dealing with enormous amount of data. Database is advantageous in accumulating enormous amount of data and in efficiently searching for data and lining it up. Building on the server side will enable independent data management and will make database available at any places through the network. Database built by the present system is consisted from four tables: user table, visitor table, exhibition exposition contents table, and user behavior table (Figure 11).

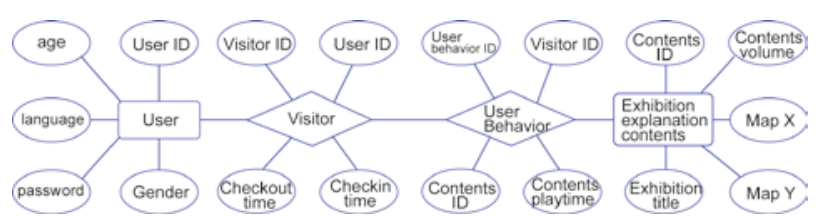

Fig. 11. Graphic display

\section{(1) User table (Table 3)}

This table saves user name (user_name), password (password), age (age), gender (gender), language (language) registered before viewing. User ID (uique_id) is issued every time a new user registers. This ID does not overlap with others and is used for identifying a user at other tables.

Table 3. A part of user table

\begin{tabular}{|c|c|c|c|c|c|c|}
\hline$\leftarrow T \rightarrow$ & unipue id & passwnrd & user _name & zender & age: & languaze \\
\hline$\Pi>x$ & 151 & 71be2adf58c9644a60 lat68289277t2508da4ab3 & tountiguk & 1 & 1 & ip \\
\hline$\square>x$ & 152 & 662670009912000600 otecief $11045004910700 \mathrm{~d}$ & rtidtalder & 1 & 0 & ip \\
\hline$\square<x$ & 153 & 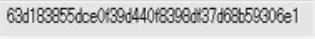 & yasato & 2 & 4 & ib \\
\hline$\square / x$ & 154 & 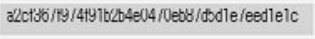 & yhahiii & 1 & 1 & ip \\
\hline$\square>x$ & 155 & 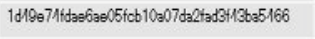 & wuhashatis & 1 & 1 & ip \\
\hline$\square \operatorname{lo}$ & 156 & 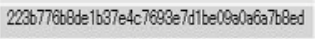 & igheustb & 1 & 1 & ip \\
\hline$\square<x$ & 157 & 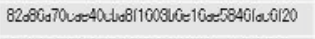 & Elyuis & 2 & 2 & iv \\
\hline$\square>x$ & 158 & 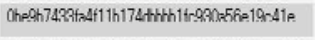 & krnnnta & $?$ & 3 & in \\
\hline $0<x$ & 159 & 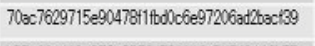 & tttttttt & 1 & 1 & ip \\
\hline$\square>x$ & 160 & b87006c100c858c8356d7640160347740116675c & ghwivish & 1 & 1 & ip \\
\hline$\square<x$ & 161 & 2 fera:5594426513cdes363tas3138488def796e4 & they:ii & 1 & 1 & b \\
\hline$\square \ln$ & 162 & $268027 a 2061052108001840 \mathrm{a}(8 \mathrm{cos} 600044 \mathrm{dd} 10 \mathrm{~d} 19$ & thesthhf & 1 & 1 & I \\
\hline
\end{tabular}

This table saves data replacing character strings such as "Male" and "Elementary school students" with numbers to make the management easy. The correspondence of the character strings and figures is shown below.

\begin{tabular}{|r|l|}
\hline Gender property value & \multicolumn{2}{|l|}{ Age property value } \\
$0-$ Unknown gender & $0-$ Unknown age \\
$1-$ Male & $1-$ elementary kids \\
$2-\quad$ Female & $\begin{array}{l}\text { high } \\
3-\quad \text { Junior and Senior }\end{array}$ \\
& $3 \sim 29$ years old \\
\hline
\end{tabular}

\begin{tabular}{|l|l|}
\hline $4-30 \sim 39$ years old \\
$5-40 \sim 49$ years old \\
$6-50 \sim 59$ years old \\
$7-60 \sim 69$ years old \\
$8-$ above 70 years old \\
\hline
\end{tabular}

\section{(2) Visitor table (Table 4)}

This table manages visitor data. A record is added to the table every time the user visits and visit ID (unique_id) is issued. Together with visit ID, user ID (user_id), viewing start time (check_in), end time (check_out), and utilized contents type (is_child), that is, if they are for adults or children are saved.

\section{Table 4. Visitor table}

\begin{tabular}{|c|c|c|c|c|c|c|c|}
\hline \multicolumn{3}{|c|}{$\leftarrow \mathrm{T} \rightarrow$} & unique_id & user_id & check_in & check_out & is_child \\
\hline$\square$ & 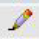 & $x$ & 264 & 267 & $2010-12-15 \quad 15: 36: 22$ & $2010-12-15 \quad 16: 05: 18$ & 0 \\
\hline$\square$ & $\theta$ & $x$ & 289 & 292 & $2010-12-16 \quad 10: 37: 45$ & $2010-12-16 \quad 11: 19: 10$ & 0 \\
\hline$\square$ & $\theta$ & $x$ & 290 & 293 & $2010-12-16 \quad 10: 47: 26$ & $2010-12-16 \quad 11: 43: 13$ & 0 \\
\hline$\square$ & $\theta$ & $x$ & 291 & 294 & $2010-12-16 \quad 10: 54: 23$ & $2010-12-16 \quad 12: 48: 17$ & 0 \\
\hline$\square$ & $\rho$ & $x$ & 292 & 295 & $2010-12-16 \quad 11: 17: 45$ & $2010-12-16 \quad 11: 59: 37$ & 0 \\
\hline$\square$ & $\theta$ & $x$ & 294 & 297 & $2010-12-16 \quad 11: 38: 16$ & $2010-12-16 \quad 12: 06: 08$ & 0 \\
\hline$\square$ & 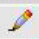 & $x$ & 303 & 306 & $2010-12-16 \quad 13: 49: 40$ & $2010-12-16 \quad 14: 44: 05$ & 0 \\
\hline$\square$ & 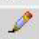 & $x$ & 304 & 307 & $2010-12-16 \quad 13: 50: 03$ & $2010-12-16 \quad 14: 43: 50$ & 0 \\
\hline$\square$ & $\theta$ & $x$ & 309 & 312 & $2010-12-16 \quad 14: 11: 02$ & $2010-12-16 \quad 15: 50: 42$ & 0 \\
\hline$\square$ & $\theta$ & $x$ & 311 & 314 & $2010-12-16 \quad 14: 16: 06$ & $2010-12-16 \quad 15: 40: 19$ & 0 \\
\hline$\square$ & $\theta$ & $x$ & 328 & 331 & $2010-12-1709: 38: 31$ & $2010-12-17 \quad 11: 47: 13$ & 0 \\
\hline$\square$ & $\theta$ & $x$ & 377 & 380 & $2010-12-17 \quad 14: 20: 22$ & $2010-12-17 \quad 14: 38: 33$ & 0 \\
\hline
\end{tabular}

Is_child property value respectively indicates the use of adult contents and child contents when 0 and 1 .

\section{(3) Exhibition exposition contents table (Table 5)}

This table saves exhibition contents data such as exhibition title (title), the contents ID (unique_id), and contents length (length). The properties of MapX and MapY are explained later at client side system explanation.

Table 5. exhibition exposition contents table

\begin{tabular}{|c|c|c|c|c|c|c|c|}
\hline \multicolumn{3}{|c|}{$\leftarrow T \rightarrow$} & unique_id & title & $\operatorname{man} X$ & $\operatorname{mapY}$ & leneth \\
\hline$\square$ & 8 & $x$ & 1 & 宮地符古鋇 & 655 & 240 & 97 \\
\hline$\square$ & $\rho$ & $x$ & 10 & 坦泾楼木 & 579 & 305 & 38 \\
\hline$\square$ & 8 & $x$ & 11 & 鳥浜貝玡さぎらり & 480 & 306 & 95 \\
\hline$\square$ & $\rho$ & $x$ & 12 & 形にこナ゙かる䋲文人 & 490 & 390 & 42 \\
\hline$\square$ & 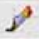 & $x$ & 13 & 万哭 & 285 & 390 & 40 \\
\hline$\square$ & 9 & $x$ & 14 & 剥取取石器土器 & 385 & 396 & 48 \\
\hline$\square$ & 8 & $x$ & 20 & 沖白 & 621 & 400 & 104 \\
\hline$\square$ & 8 & $x$ & 22 & 王の出現 & 555 & 380 & 112 \\
\hline$\square$ & 8 & $x$ & 26 & 埴䎾之石人の立つ凨卓 & 765 & 485 & 52 \\
\hline$\square$ & 9 & $x$ & 27 & 装斯古嘪 & 680 & 475 & 32 \\
\hline$\square$ & 2 & $x$ & 80 & 漠字文化の応がけ & 700 & 375 & 43 \\
\hline$\square$ & $\Leftrightarrow$ & $x$ & 31 & 仙侅 & 695 & 305 & 39 \\
\hline$\square$ & 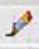 & $x$ & 33 & アジア人の理想の姿 & 915 & 435 & 97 \\
\hline$\square$ & $s^{4}$ & $x$ & 34 & か、、すず・たいこ & 915 & 325 & 45 \\
\hline
\end{tabular}




\section{(4) User behavior table (Table 6)}

This table summarizes who used which exhibition exposition contents for how long. It saves User behavior ID (unique_id), visitor table visit ID (visit_id), exhibition exposition contents table contents ID (exhibit_id), contents play duration (appreciation_sec).

Table 6. A part of user behavior table

\begin{tabular}{|c|c|c|c|c|c|c|}
\hline \multicolumn{3}{|c|}{$\leftarrow \mathrm{T} \rightarrow$} & unique_id & visit_id & exhibit_id & appreciation_sec \\
\hline$\square$ & $\theta$ & $x$ & 36 & 3 & 55 & 16 \\
\hline$\square$ & $\theta$ & $x$ & 37 & 3 & 1 & 31 \\
\hline$\square$ & 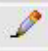 & $x$ & 38 & 3 & 10 & 22 \\
\hline$\square$ & $\theta$ & $x$ & 39 & 3 & 35 & 34 \\
\hline$\square$ & $\theta$ & $x$ & 40 & 3 & 43 & 21 \\
\hline$\square$ & 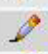 & $x$ & 41 & 3 & 45 & 7 \\
\hline$\square$ & $\theta$ & $x$ & 42 & 3 & 53 & 21 \\
\hline$\square$ & $\theta$ & $x$ & 43 & 3 & 55 & 16 \\
\hline$\square$ & $\theta$ & $x$ & 44 & 3 & 1 & 31 \\
\hline$\square$ & 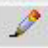 & $x$ & 45 & 3 & 10 & 22 \\
\hline$\square$ & 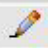 & $x$ & 46 & 3 & 35 & 34 \\
\hline$\square$ & 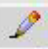 & $x$ & 47 & 3 & 43 & 21 \\
\hline$\square$ & 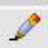 & $x$ & 48 & 3 & 45 & 7 \\
\hline
\end{tabular}

\subsubsection{Data totalization}

Server side system totalizes data in accordance with the request from client side system explained later. Totalized data is summarized in XML format and sent out to client side.

\subsection{Data processing and presentation}

Data saved to the server is a set of character strings so curators may have difficulty in efficiently utilizing it as it is. Data will be presented in a simple form visually arranging a set of character strings into graphs and tables. Reducing sentences and text data on the display as much as possible will allow curators to intuitively recognize data (user) tendency. Data processing and presentation are carried out at client side system. Figure 12 shows the client side system use screen.

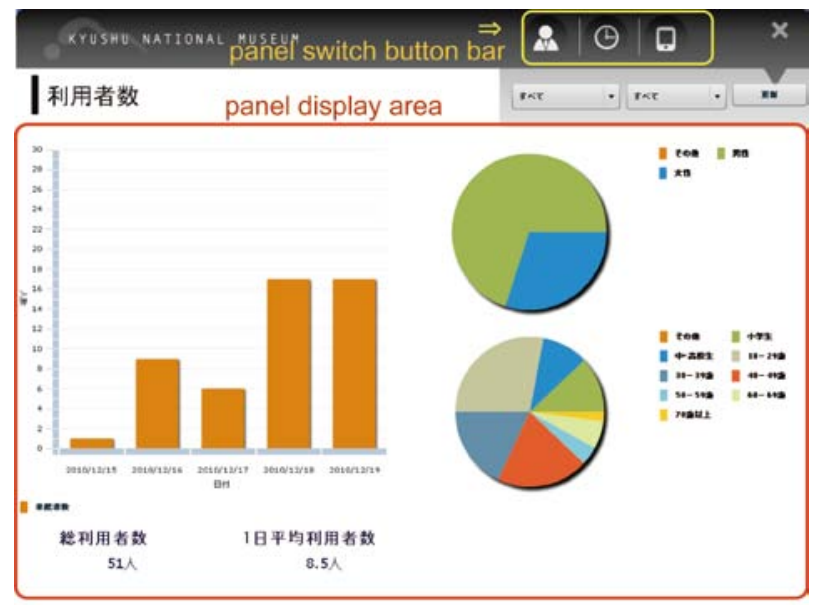

Fig. 12. Client side system use screen

Curator can access and process all data with only mouse operation at this system.
Making icons interactive to mouse and expressing data change in animation will make the interface available for easy operations and understandings for curators. The system requests data from server side system according to system input data when a curator operates. The present system has three panels: user panel, average stay hour panel, and exhibition viewing frequency panel. Wanted data can be checked by switching panels displayed to "panel display area” using panel switch button bar on the upper right. Below is the three panels (Figure 13).

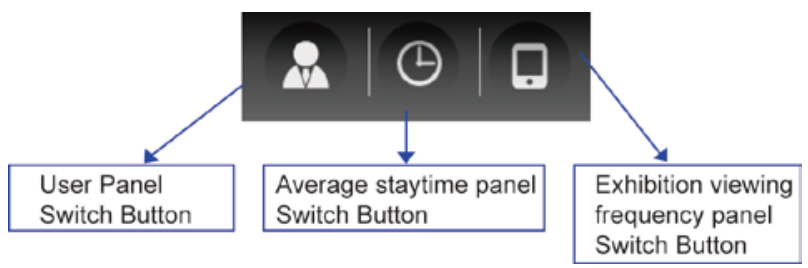

Fig. 13. Panel switch button bar

\subsubsection{User number panel}

It is a panel displaying system user number (Figure 12).

\section{(1) User number panel}

Left side of the panel is a user number column chart for a day and the right side shows the proportion of genders and ages by a pie chart. A column chart is an effective way to compare user numbers a day and a pie chart is an effective way to present ratios of each element of genders and ages. Y-axis and $\mathrm{X}$-axis of the column chart are respectively correspondent to "number of people" and "date." Placing mouse on the graphs will show detailed data (accurate values). "Total user number" and "average user number a day" are also displayed.

\section{(2) Detailed user search}

User number panel allows user number research selecting gender and age conditions. Two combo boxes at the upper right enable age and gender selection (Figure 14). Options of ages and genders at the combo boxes are the same with previewing registration. The combo box enables curators to check gender and age tendencies.

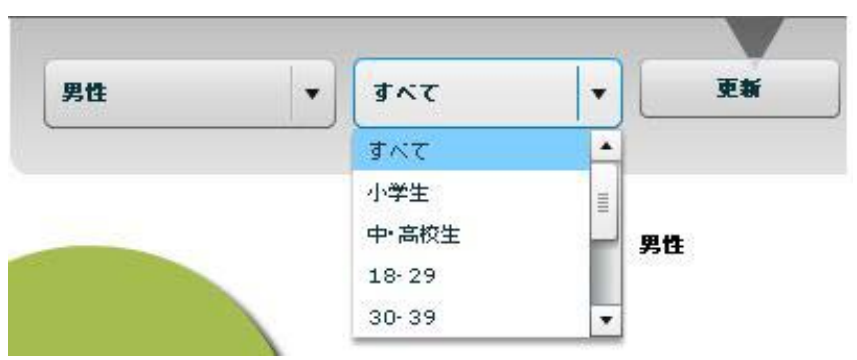

Fig. 14. Combo box

For example, respectively choosing "Male" and "18-29" at gender selection combo box and age selection combo box and clicking update button will show a pie chart and a column chart of the selected conditions (Figure 15). 


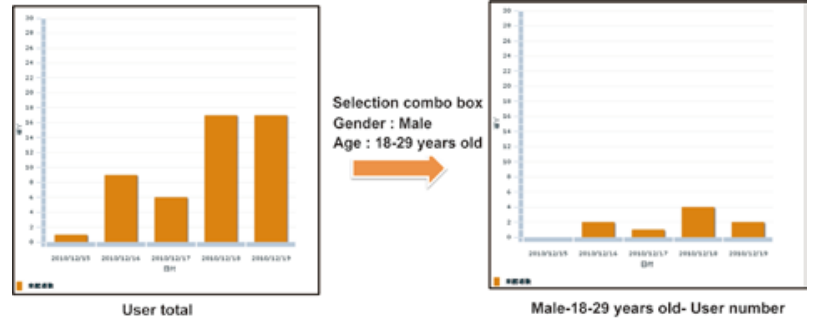

Fig. 15. Data detailed search function

\subsubsection{Average stay duration panel}

It is a panel showing user average stay duration (Figure 16).

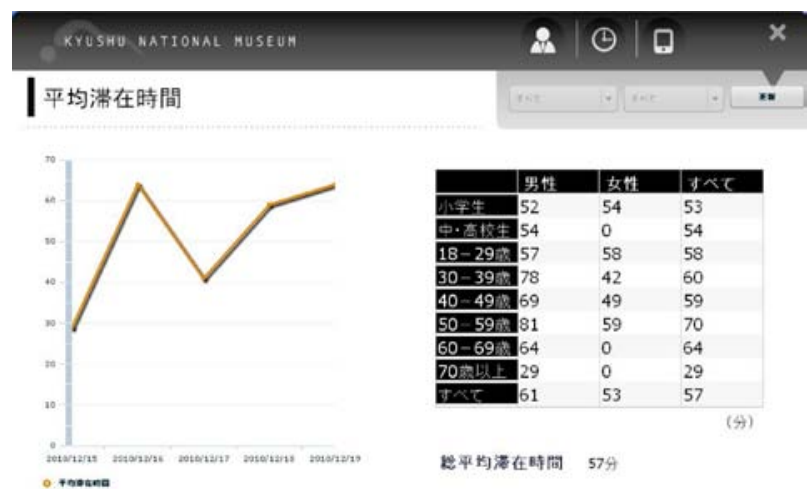

Fig. 16. Average stay period panel

The left side of the panel is a line graph of average stay period a day and the right side shows a table of average stay duration separating genders and ages.

A line graph is excellent at showing time series shift and the present panel shows the shift of user average stay duration. $\mathrm{Y}$-axis and $\mathrm{X}$-axis of the graph respectively corresponds to "duration" and "average stay duration." Consecutive data collection can realize the comparison among seasons or the comparison with last year of the same month. When a curator would like to check an accurate value, putting the mouse over the plotted dots will show the value. The right table clearly shows that there is a difference in staying duration depending on ages and genders. Progress in data accumulation will show accurate average staying duration classified by gender and age.

\subsubsection{Exhibition viewing frequency panel}

It is a panel displaying user exhibition viewing frequency (Figure 17). Exhibition viewing frequency is computed from user operation history saved to database. The present panel is composed of "viewing frequency display area" which displays user exhibition viewing frequency, "exhibition table list" for selecting and searching each exhibition, ad "Sort map switch button” which switches exhibition viewing frequency display methods. Each role and function are shown hereafter.

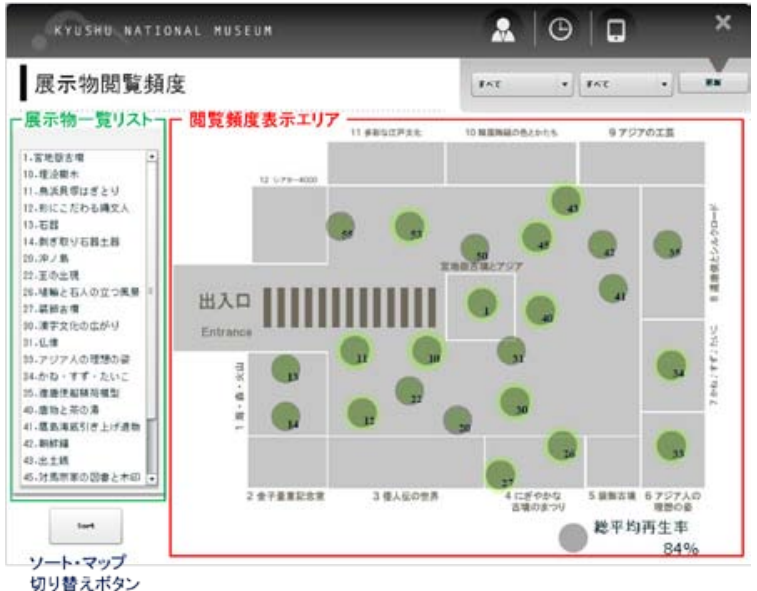

Fig. 17. Exhibition viewing frequency panel

\section{(1) Roles and functions of viewing frequency display area}

In order to visualize data user exhibition viewing frequency is expressed by the size of circles at viewing frequency display area. Each circle is corresponding exhibition and the larger the circle size is, the higher the viewing frequency is (the circle visualizing viewing frequency is called circle data hereafter). Average play rate of every content is adopted as a viewing frequency indicator. It is a value expressed by a percentage dividing contents length with average play hour. For example, average play rate can be computed by

$$
\beta \div \alpha \times 100
$$

when contents length is $\alpha$ seconds and average play hour is $\beta$ seconds. Comparison of average play rate value will let us know an appropriate exposition contents length. Circle data holds two values: each content average play rate and all contents average play rate. Figure 18 shows an enlarged drawing of circle data.
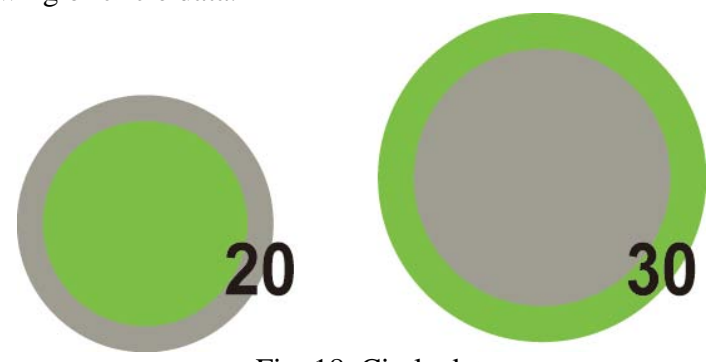

Fig. 18. Circle data

One circle data is composed of two circles, gray circle expressing all contents average play rate and green circle expressing each content average play rate. The comparison of the two circles will make it easier to compare each and all contents average play rate. For example, the left circle data of Figure 17 has a gray circle larger than a green circle, which shows that the content has an average play rate below the overall average. On the other hand, the right circle data has green circle larger than gray one, which shows the content has play rate above the overall average. Exhibition contents ID is displayed at the center of each circle data. This contents ID corresponds to exhibition exposition contents table contents ID (unique_id) saved at database. 
Circle data is display on the map in order to work together with positioning information. Position on the map is the value of MapX and MapY of exhibition exposition contents table. Rather than displaying evaluation results by only a single exhibit, it is easier to grasp the change in relationships between exhibits and in viewing when displayed on a map even if exhibition place has been changed. Overall exhibition exposition contents average play rate (total play rate average) is also displayed at the lower right of viewing frequency display area. On the other hand, there can be a case when a curator would like to check a concrete figure. When detailed information check is wanted, clicking the circle data on the map will open another window and a value is displayed. Figure 19 shows exhibition play rate display window.

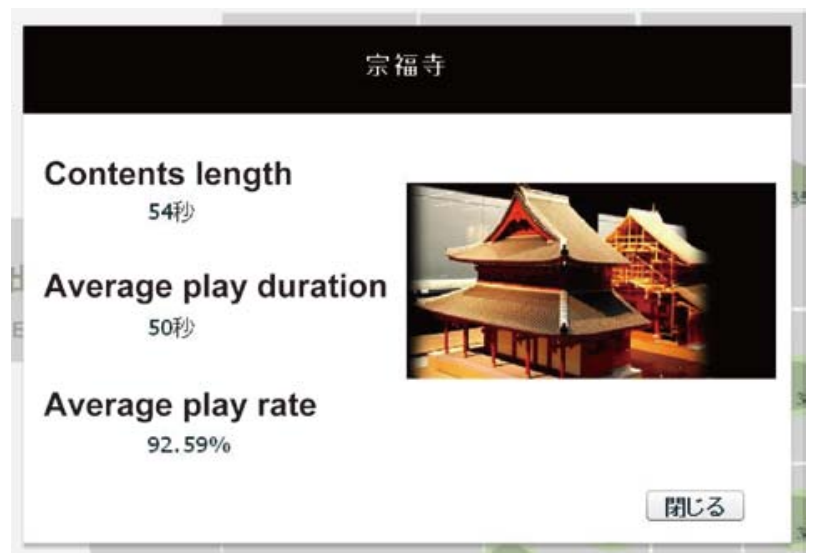

Fig. 19. Exhibition play rate display window

Each exhibition exposition contents length, average play duration, and average play rate can be checked here. Displaying exhibition picture makes it clear what the data is about.

\section{(2)Roles and functions of exhibition table list}

Exhibition table list supports curators to look for the desired exhibit by displaying a list of exhibition (Figure 20 left). Exhibition exposition contents table contents ID (unique_id) and exhtiion title (title) saved to database will be displayed on the list. When a curator selects a desired exhibition title, circle data corresponding to viewing frequency display area will be selected. A curator clicks the selected circle data, opens the aforementioned exhibition play rate display window, and checks detailed values for each exhibition.

\section{(3) Roles and functions of sort/map switch button}

Displaying circle data on the map is for grasping user tendency from the exhibition position relationship in the museum. However, sometimes it is difficult to compare which ones have higher average play rate when there is no big difference in the circle sizes or when exhibition positions are far from each other. The sort/map switch button is to change circle data display methods so that the difference between average play rates can be obtained. Figure 20 shows a display method.

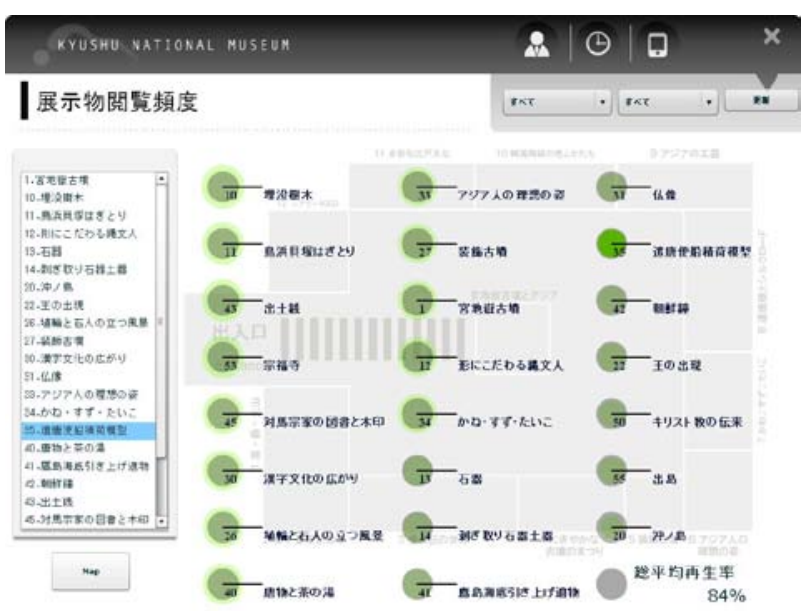

Fig. 20. Circle data arrangement

Circle data is arranged and displayed according to play rate from upper left. Lining up as though will let curators grasp which exhibition exposition contents have high average of play rate. Display method switch expresses the movement of circle data in animation in order to obviously indicate that data display methods have been changed. This display method is not incorporated with museum positions so exhibition titles are displayed to make it clear which circle data is corresponding with which exhibition.

\subsubsection{Data transmission methods among systems}

Client side system requests data from server side system at all panels. Server side/ client side system data transmission method will be explained (Figure 21).

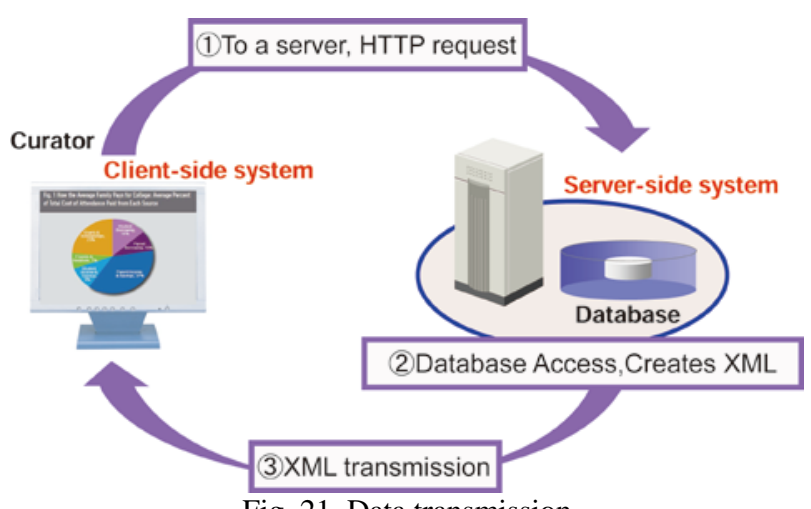

Fig. 21. Data transmission

\section{(1) Client side system data request}

When client system is booted or when there are some kinds of input by a curator, it requests necessary data for server side system.

\section{(2) Server side system response}

Server side system creates queries (question items) in accordance with the value sent from client side system. The queries are used for database inquiry.

\section{(3) Data transmission to client side system}

It totalizes data gained by the inquiry, summarizes into XML format corresponding to each panel and sent to client side system. 


\section{CORROBORATE EXPERIMENT AT KYUSHU NATIONAL MUSEUM}

System corroborate experiment has been taken place at Cultural Exchange Exhibition room, permanent exhibition at Kyushu National Museum from December 14, 2010 to December 19, 2010. This chapter shows user data result gained at the corroborate experiment evaluation system.

\subsection{Building corroborate experiment environment}

Access point setting locations have been decided selecting object exhibition and considering the exhibition place. Experiments are shown hereafter conducted to decide access point setting locations and to build positioning information database. The experiments have taken place at Kyushu National Museum Cultural Exchange Exhibition room for seven times in total.

\subsubsection{Area division}

Distances between object exhibitions are measured and Cultural Exchange Exhibition room has been divided into eleven areas depending on the field intensity sent out from Wi-Fi access points.

\subsubsection{Access point setting location determination}

It is determined so that the user can be positioned and the user does not get disturbed during viewing. The present system collects radio wave information from multiple access points and decides the locations. Another setting method is to let the object exhibition to have one-to-one correspondence with an access point. However, there may be no access point setting location depending on the exhibition cases and radio wave sent out from access points may have restrictions such as being influenced by obstacles and changing depending on the museum environment so multiple access points have been set in each area.

\subsubsection{Positioning information database building and} update

After setting access points, positioning information accuracy has been improved by updating positioning information database while checking information from access points by iPad (Figure 22).

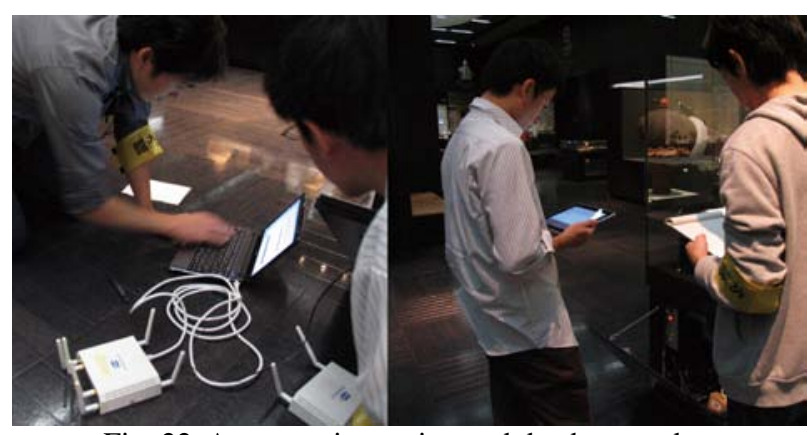

Fig. 22. Access point setting and database update

\subsection{Corroborate experiment flow}

User data collection as a part of corroborate experiment by exhibition evaluation support system is shown below. Ten iPads have been prepared for rental. We let visitors borrow $\mathrm{iPad}$ at the museum reception counter. When borrowing, users registered their information before viewing.
Using the iPad visitors borrowed, they watch around exhibition. Exhibition evaluation support system collects user behavior data. After viewing, devices will be returned and data acquisition situations are checked and we asked curators in the museum who used the evaluation system what they think of the system.

\subsection{Details of collected user data}

User data details will be explained which exhibition evaluation support system has successfully collected at personal museum concierge corroborate experiment. User data collected at previewing registration is shown in Table 7.

Table 7. User data collected at previewing registration

\begin{tabular}{|c|c|c|c|c|}
\hline & Male & Female & Unknown & Total \\
\hline Elementary & 3 & 3 & 0 & 6 \\
\hline $\begin{array}{c}\text { Junior and } \\
\text { Senior high }\end{array}$ & 5 & 0 & 0 & 5 \\
\hline $\begin{array}{c}\text { 18-29 years } \\
\text { old }\end{array}$ & 9 & 5 & 0 & 14 \\
\hline $\begin{array}{c}\text { 30-39 years } \\
\text { old }\end{array}$ & 5 & 4 & 0 & 9 \\
\hline $\begin{array}{c}\text { 40-49 years } \\
\text { old }\end{array}$ & 8 & 2 & 0 & 10 \\
\hline $\begin{array}{c}\text { 50-59 years } \\
\text { old }\end{array}$ & 1 & 1 & 0 & 2 \\
\hline $\begin{array}{c}\text { 60-69 years } \\
\text { old }\end{array}$ & 3 & 0 & 0 & 3 \\
\hline Above 70 & 1 & 0 & 0 & 1 \\
\hline Unknown & 0 & 0 & 1 & 1 \\
\hline Total & 35 & 15 & 1 & 51 \\
\hline
\end{tabular}

Total user number collected by previewing registration is 51 . Those people also provided valid staying duration at the museum. We have succeeded in collecting 1013 pieces of data about user mobile device operation history (exhibition exposition contents play situations). However, sometimes we failed to collect data although we had users use the system. Main reasons are that some users ended iPad application in the middle of viewing, iPad memory ran out and forced to terminate, or malfunctioning of network environment prevented database access.

\section{EVALUATION AND DISCUSSION}

This chapter discusses curator system evaluation and the result.

\subsection{Evaluation from curators}

We had curators at Kyushu National Museum involved in exhibition use our system and evaluate it. The system presents obtained data from corroborate experiment at client side system.

Kazutaka KAWANO, Cultural Exchange Exhibition room chief, Kyushu National Museum

Data collection related to exhibition evaluation is successful. We just need to discuss exhibition evaluation methods and 
necessary data for the evaluation wit curators. Various exhibition evaluation methods exist so flexible handling is the best. Desired information could be found with mouse operation using the system. I think we need a hypothesis which links desired information with objective data. It is effective that visitor data is automatically collected without visitor being conscious of it and data totalized results have been visualized. Actual introduction of the system to museum largely relies on cost-effectiveness issue but obtained data by automation and systemization is effective for exhibition evaluation. By combining objective data collection and questionnaire for visitor satisfaction degree expression will enable compound exhibition evaluation.

Yuki SAKAMOTO, planning department, Kyushu National $\underline{\text { Museum }}$

Data collection related to exhibition evaluation is successful. We need to raise statistical credibility by collecting more samples (visitor data amount). Actual use at museums will accumulate data and will raise data credibility. Presentable data is still limited so it is desirable to present significant data by combining each data value. Staying duration data can be referred. It is expected that young generations would like to use the devices. Device utilization seems to restrict who borrows a device. System development has possibility to present other visitor data so it is intriguing. I would like to hope development of data focus, collecting methods and presenting methods. Not only average play rate but also the actual number of people who plays is also needed.

\subsection{Discussion}

Highly advanced information society values communication and museum evaluation and exhibition evaluation are required these days. Exhibition is evaluated by curators and the result is utilized to promote smooth communication between visitors and exhibition. Exhibition without considering visitors may reduce overall message of exhibition. Knowledge gained from visitor behavior and exhibition improvement is considered to raise visitor satisfaction.

The present research built exhibition evaluation support system for curators. Mobile devices, server side, client side system each played their role to automatically collect visitor data and totalize and present. Automatically collecting objective data such as "position" and "time" enabled visitors to be unconscious of the research and efficiently positioning information and mobile device operation history have been collected. Arranging visitor data visually in view of information design, we have developed interface curators can intuitively grasp visitor behavior tendency. Client side system exhibition viewing frequency panel expresses visitor exhibition viewing frequency with the size of a circle and maps the museum which allows grasping position relationships and big and small relationships. System is interactive and is capable of searching desired data. However, some problems have been revealed through Kyushu National Museum corroborative experiment. Exhibition evaluation support system collects user data by an iPad application and sends data to server after viewing but when some kind of troubles occur to the network and cannot get connected, collected data will not be saved to server and just finish. System must be improved so that data saving should not be influenced by network environment.
Positioning information accuracy needs to be higher.

Tracks data of visitors at exhibition has an important meaning. Tracks of visitors let us know structural issues of exhibition and clues for exhibition arrangement. Detecting visitor appreciation behavior pattern will enable us to intentionally guide visitors. It can be effective data when designing various exhibition appreciation plans suitable for user ages and visit objectives.

This time Cultural Exchange exhibition room at Kyushu National Museum was divided into eleven areas for experiment but there were sometimes gaps between the real position of the visitors and the position system recognizes. Positioning information is effective data to know user behavior so accurate data collection and smaller area setting are required. We intend to improve information positioning accuracy from a suitable combination of position computing methods and access point setting methods. We had curators use the system for verification. It has been highly evaluated at providing data from different view and efficient exhibition evaluation thanks for automation. The present system utilization will reduce burdens for curators, exhibition planners and designers, making exhibition evaluation easy and create repeaters from various visitor information collections.

We would like to discuss what kind of visitor data museums require and how to present them with curators and improve the system. It may be possible to propose more accurate evaluation methods by combining collected data with the present system and with the conventional research methods. We hope building the present system will improve visitor satisfaction.

\section{REFERENCE}

[1] Joongyoup Lee,Daewoong Kim,Developing and Evaluation of Visitor's Behavior Evaluating System for Exhibition Facilities, JSSD, vol.55,no.4,2008, pp.77-86.

[2] Joongyoup Lee,Daewoong Kim,Basic Investigation for Contents Design of Portable Voice Guide System,JSSD,vol.55, no.4, 2008, p67-76.

[3] Toru Takahashi, Kenichi Kato, Yoshiyuki Nakamura, "User Acceptance of Related Information Guide on Mobile Guidance in a Museum”, The 22nd Annual Conference of the Japanese Society for Artificial Intelligence, Proc.vol.22,no.3C3-01, 2008

[4] Syuji Takashina,Yutaka Mino, Museum Power, Keio University Press, 2006.

[5] Ben Fry,Visualizing Data,Exploring and Explaining Data with the Processing Environment, O'Reilly Media, 2008.

[6] Robert Klanten,Thibaud Tissot, Data Flow:Visiualising Information in Graphic Design, Die Gestalten Verlag, 2008.

[7] Robert Klanten, Sven Ehmann, Nicolas Bourquin, Thibaud Tissot, Data Flow 2- Visualizing Information in Graphic Design, Die Gestalten Verlag, 2010. 


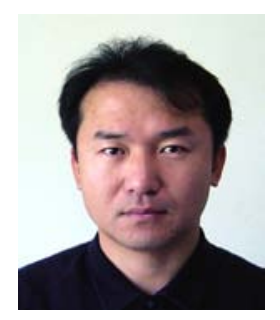

\section{Dae-Woong Kim}

Faculty of Design, Kyushu University

Completed master's course at Graduate School of Design, Kyushu Institute of Design in 1998. An instructor at Department of Art and Information Design, Kyushu Institute of Design, from 2002.An associate professor at Department of Art and Information Design, Kyushu Institute of Design, from 2005 till now. Engage in research on digital contents and digital archive. A member of JSSD, the Japan Society for Exhibition Studies, Design Research Association, ADADA.

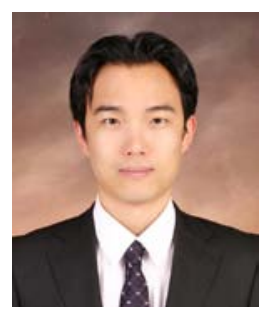

\section{Joong-Youp Lee}

Faculty of Design, Kyushu University Completed master's course at Graduate School of Design, Kyushu University in 2006.

Completed doctoral course in 2009.

Postdoctoral academic researcher at Department of Contents Creative Design, Kyushu University from 2009 till now. Engages in research on contents design, interface design and etc. A member of JSSD, Design Research Association, ADADA.

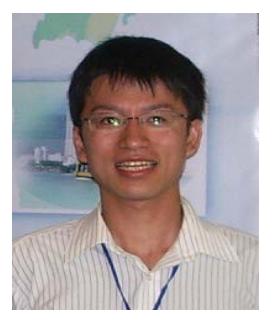

\section{Kousuke Kaneko}

(PhD student) Department of Informatics, Graduate School of Information Science and Electrical Engineering, Kyushu University. Research filed: serious game, positioning information system, three dimensional image processing. A member of IPS, IGDA, DiGRA JAPAN. 